\title{
The Influence of Maternal-Acceptance Experiences During Childhood, Social-Supportive Level and Emotion-Coaching Reaction on Child Emotion-Regulation Strategies: Mediated-Moderation Effects
}

Ji-Hyun Oh

Department of Counseling Psychology, Chosun University, Gwangju, Korea

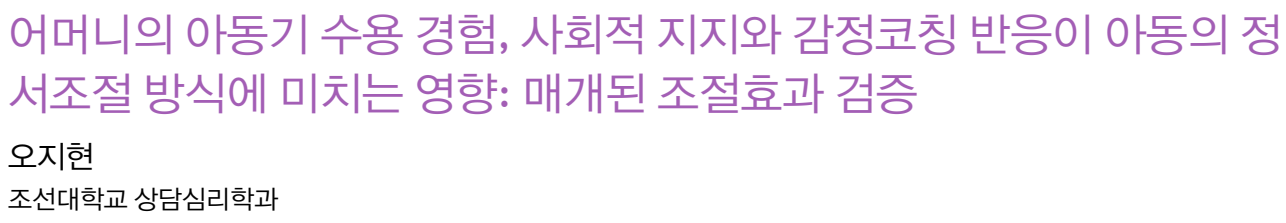

Objective: The study examined the mediated-moderation effect of social-support levels from maternal-acceptance experiences by the parents of origin to child emotion regulation strategies through an emotion-coaching reaction.

Methods: The participants in this study were children (Grades 4-6) and their mothers. They completed questionnaires on Maternal Parenting Experiences Scale, Children's Emotion Regulation Scale, Emotion-Coaching Scale, and Social Supportive Level Scale. Data were analyzed via SEM.

Results: The main findings were as follows. First, a mediating model showed that the relationship between maternal-acceptance experiences by the parents of origin and child emotion-regulation strategies was mediated by emotion-coaching reactions. Second, there was a moderation effect of social-supportive levels on the relationship between maternal-acceptance experiences from parents of origin and emotion-coaching reaction. Finally, social-supportive levels mediated the moderation effect of social-support level from maternal-acceptance experiences to child emotionregulation strategies through emotion-coaching reaction.

Conclusion: These results indicate that importance of maternal social-supportive level from owns spouse or friends. I discussed the implications of the intervention of parent counseling and parent education in this research.

Keywords: maternal-acceptance experiences during childhood, emotion-coaching reactions, socialsupportive level, child emotion-regulation strategies, mediated-moderation effects

Corresponding Author: Ji-Hyun Oh, Department of Counseling Psychology, Chosun University, 309, Philmundaero, Dong-gu, Gwangju, Korea E-mail: ojh@chosun.ac.kr
(C)The Korean Association of Child Studies

This is an Open Access article distributed under the terms of the Creative Commons Attribution Non-Commercial License (http:// creativecommons.org/licenses/by-nc/4.0) which permits unrestricted noncommercial use, distribution, and reproduction in any medium, provided the original work is properly cited. 


\section{서론}

아동의 지각관련 두뇌 영역은 유아기에 성장이 완성되지만 정 서적인 측면을 관장하는 전두엽은 사춘기 후반인 18 세에 이 를 때까지 성장을 계속한다. 아동기의 경험들은 정서지능에 영향을 미치고 정서능력의 틀을 형성하는 시기라 할 수 있다 (Goleman, 1995). 특히, 또래관계가 확대되면서 폭넓은 사회 적 관계를 형성해가는 시기인 후기 아동기의 경우 정서조절은 타인과 긍정적인 관계형성 및 상호작용에 필수적인 능력이다 (Cole, Martin, \& Dennis, 2004). 정서조절에 대한 개념은 환경 과 상호작용을 의미하며 학자들마다 기능적 관점에 따라 다양 한 정의를 내리고 있다. 기존에는 단순히 공격적 행동 같은 부 정적 행동들의 억제로 여겨지다가 개인이 특정 정서를 유발하 는 상황에서 그 정서를 조절하기 위해 사용하는 대처능력으로 정의하면서, 성공적인 대인관계를 가능하게 하는 정서조절 방 식이 보다 강조된다(Calkins, 1994; Lim, 2001).

이러한 정서조절은 부모와 자녀 간 원만한 관계에서부터 시작되며(Salovey \& Mayer, 1996), 부모-자녀관계는 아동의 정 서조절 방식에 영향력이 높은 주요한 요인으로 꼽힌다. 특히 어머니는 자녀에게 중요한 외적 환경이며 자녀의 정서능력에 강력한 영향을 준다. 예를 들어, 어머니의 정서조절 방식 및 정 서표현은 아동에게 모델이 되고 자녀와의 상호작용을 통해 아 동이 정서에 대해 학습할 수 있는 기회를 제공한다(Denham,

Renwick-Debardi, \& Hewes, 1994).

이와 관련하여 Belsky와 Pensky (1990)의 양육행동 결정과 정 모델에서 아동의 정서 및 사회성발달에 영향을 미치는 요 인 중 부모의 어릴 적 원부모의 양육방식을 강조한 바 있다. 다시 말해, 어머니 자신의 어린 시절 원부모에 대한 애착표 상 및 양육경험이 이후 자신의 양육행동에 가장 많은 영향을 주는 요인이며(Cowan, Cohn, Cowan, \& Pearson, 1996; Y. J. Jeong, 2008), 이는 아동의 심리사회적 적응과 정서능력에 영 향을 미치는 것으로 밝혀졌다. 구체적으로 살펴보면, 어머니 가 원부모에게 받은 거부 경험이 자녀의 타인정서인식 능력 과 자기-타인정서조절 능력에 부정적인 영향을 주는 것으로 나타났다(E.-K. Kim \& Song, 2009). 또한, 아동기 원부모의 양 육방식을 부정적으로 지각하는 어머니가 자녀에게 보이는 부 정적인 양육행동은 유아의 위축(S.-H. Lee, Lee, \& Min, 2006), 사회적 능력(Chae \& Lee, 2009), 학령기 아동의 부적응(M. K. Jeong \& Kim, 2003)을 예측하는 것으로 나타났다. 상기한 바 와 같이 아동기 원부모의 양육방식은 부모 자신의 양육행동 으로 이어지고 이는 아동의 정서조절에 영향을 주는 주요한
변인임을 알 수 있다.

한편, 아동의 정서능력에 영향을 미치는 어머니의 양육행 동을 보다 구체적으로 설명하기 위하여 Eisenberg, Cumberland 와 Spinard (1998)는 정서관련양육행동을 강조하였고, 자녀의 부정적 정서표현에 대한 부모 반응에 주목하였다(Eisenberg \& Fabes, 1994; Morris, Silk, Steinberg, Myers, \& Robinson, 2007). Eisenberg 등(1998)이 아동의 정서사회화에 관련된 연구들을 종합한 발견적 모델에 의하면 자녀의 정서표현에 대한 부모 반응은 아동의 정서경험, 정서의 이해와 조절, 정서표현에 직 접적 혹은 간접적인 영향을 주는 요인임을 보고한다. 이러한 과정에서 아동은 자신과 타인의 정서를 이해하고 경험하며 조 절하는 것을 학습할 수 있다. 뿐만 아니라, 자녀의 부정적 정서 표현에 대해 감정을 존중하고 수용하는 반응과 더불어 아이가 스스로 문제를 해결하도록 이끌면서 행동에 한계를 정해주는 감정코칭 반응은 아동이 정서를 명확히 인식하고 표현하며 조 절하는 등의 건강한 정서발달을 돕는다(Oh, 2014). 예를 들면, 어머니가 자녀의 부정적 감정을 수용하고 지도하는 감정코칭 반응을 빈번하게 보일수록 아동, 청소년의 분노정서 조절과 의도적 통제능력이 증진되고(Shortt, Stoolmiller, Smith-Shine, Eddy, \& Sheeber, 2010; Valiente, Lemery-Chalfant, \& Reiser, 2007; Yap, Allen, Leve, \& Katz, 2008), 아동의 탄력성과 정서표 현 및 정서조절에도 긍정적인 영향을 미치는 것으로 나타났다 (Oh, 2013). 즉, 어머니가 자녀에게 감정코칭 반응을 많이 할 수록 아동은 적응적인 정서조절 방식이 증진됨을 알 수 있다.

자녀의 부정적 정서표현에 대한 어머니 반응은 어머니 의 정서표현에 대한 신념에 따라 차이가 있다는 연구결과(Y. Jeong \& Park, 2012)를 고려해 볼 때, 원부모와의 아동기 경험 과도 밀접한 관련이 있음을 예상해 볼 수 있다. 즉, 원부모의 양육방식은 어머니의 정서신념과 정서조절양식에 영향을 주 고, 이후 본인의 자녀에게 보이는 정서관련양육행동으로 이어 짐을 예상해 볼 수 있다. 이와 같은 관점에서 어머니의 감정코 칭 반응을 직접적으로 다룬 연구는 아니지만 아동기 원부모에 게 받은 양육경험과 자녀 양육행동 간 관련성을 탐색한 선행 연구(Kwon, 2011; J. S. Lee \& Chung, 2007)를 살펴보면, 어머 니가 원부모에게 받은 수용 경험이 많다고 지각할수록 본인도 자녀에게 긍정적인 양육태도를 보이는 것으로 나타났다. 또 한, 원부모에게 받은 수용 경험이 어머니의 정서조절 및 정서 반응 태도, 양육행동 등을 통해 자녀의 정서능력, 또래관계 및 사회적 유능성에 영향을 주고 있는 것으로 나타난 연구결과들 (Chae \& Lee, 2009; M. K. Jeong \& Kim, 2003; E.-K. Kim \& Ha, 2010; E.-K. Kim \& Song, 2009)을 근거로 어머니의 아동기 수 
용 경험이 감정코칭 반응을 통해 아동의 정서조절 방식에 미 치는 영향을 추론해 볼 수 있겠다.

그러나 어머니의 감정코칭 반응이 과거 원부모의 양육방 식에서만 영향을 받는 것은 아니다. 원부모와의 관계에서 수 용보다 거부를 경험한 성인이라고 해서 모두 부정적인 양육 태도로 이어지는 세대 간 전이가 나타나지는 않았다(Chang \& Cho, 2014). 애착이론(Bowlby, 1969; 1973)에서 부모-자녀 관 계에서 형성된 아동의 자기-관계-세상에 대한 도식이 내면화 되어 이후 성인기 부부관계 또는 자녀와의 관계에 영향을 미 치는 세대 간 전이를 강조하기도 하지만, 성장하면서 새로운 관계경험을 통해 도식은 변화 가능하다고 보고한다. 이는 초 기의 부정적 관계로부터 영향을 받은 개인의 조절방식은 이 후 건강하고 긍정적인 관계경험에 의해 적응적으로 변화될 수 있음을 의미한다. 이와 같은 관점에서 상담 및 심리치료 분야 의 연구결과 또한, 치료 성과의 $30 \%$ 는 관계요인에 의한 것임 을 밝힌 바 있고(Lambert, 1992), 이후에도 치료적 관계의 중요 성에 대한 연구는 다양한 치료적 전통을 배경으로 하는 임상 가들의 믿음과 맥락을 같이 한다(Scott, Barry, Mark, Mark, \& Barry, 1996). 치료성과의 결정적 요인인 강력한 치료적 관계는 치료자의 따뜻한 공감, 존중, 온정, 인정 등으로 보고된다. 이 는 앞서 언급한 긍정적인 관계 경험의 개념과 유사함을 알 수 있다. 즉, 아동기에 부모로부터 거부감을 경험한 관계가 지속 되었다 하더라도 이후 형제, 친구 및 배우자에게 따뜻한 공감 과 지지를 받는 경험을 통해 자기-관계-세상에 대한 도식의 변 화를 가져다 줄 수 있으며 자신의 자녀양육에 있어서 긍정적 태도로 이어질 수 있음을 예상해 볼 수 있다. 따라서 어머니의 감정코칭 반응을 탐색할 때 아동기 원부모의 양육방식만이 아 니라 이후의 사회적지지 체계를 함께 고려해 볼 필요가 있다. 사회적지지란 한 개인에게 있어서 부모, 형제, 친구 및 배우자 와 같이 중요한 타인으로부터 얻을 수 있는 물질적, 정서적, 평 가적, 정보적 지지의 긍정적인 자원을 의미한다. 이러한 타인 의 긍정적 관심과 격려, 지지와 조언의 지속적인 경험은 긍정 적 자기-타인 상에 영향을 주며 높은 자존감으로 이어진다. 다 시 말해, 어머니의 아동기 원부모에게 받은 수용 경험이 감정 코칭 반응에 영향을 주는데 있어서 사회적지지 수준은 조절변 수의 역할을 할 것으로 예상하는 바이다.

요컨대, 아동의 정서조절방식에 어머니의 아동기 수용 경 험이 영향을 미치는 과정에서 어머니의 감정코칭 반응이 매 개할 것이라는 가설을 세워볼 수 있고, 그 과정에서 사회적지 지 수준의 역할을 확인하고자 매개된 조절모형을 연구모델로 설정하였다. 매개된 조절모델(mediated moderation model)은
조절변수가 존재하는 모델에서 매개변수가 추가로 투입된 모 델이다. 즉, 독립변수와 조절변수가 결합하여 상호작용변수 가 포함된 모델에 매개변수가 새롭게 투입된 모델의 형태이 다(Hayes, 2013; Muller, Judd, \& Yzerbyt, 2005; Wu \& Zumbo, 2007). 이는 독립변수, 조절변수, 상호작용변수가 종속변수에 미치는 직접적인 영향과 이들 변수가 매개변수를 통해 종속변 수에 간접적으로 영향을 미치는 간접효과를 측정하는 것이 목 적이 된다. 즉, 아동기 수용 경험과 사회적지지 수준이 상호작 용하여 어머니의 감정코칭 반응에 영향을 미치고 이로 인한 조절효과가 감정코칭 반응을 매개로 하여 아동의 정서조절 방 식에 영향을 미치는지를 매개된 조절모형을 통해 검증하고자 하였다.

연구방법과 관련하여 지금까지 아동학을 포함한 다양한 연 구 분야에서 매개효과와 조절효과를 검증하고자 하는 연구자 들이 회귀분석을 사용한 경로분석(path analysis)을 많이 활용 하였다. 반면, 최근에는 구조방정식 모델을 이용하여 매개모 델과 조절모델을 분석하는 것이 더 적절함을 강조하고 있다 (Wu \& Zumbo, 2007). 특히 다수의 독립변수, 매개변수, 종속 변수를 한 모델에 분석할 수 있으며 모델의 적합성을 판단할 수 있다는 장점 때문에 형태상으로도 복잡한 매개모델과 조절 모델이 결합된 '매개된 조절모델'이나 ‘조절된 매개모델'효과 의 구현도 가능하다. 이는 구조방정식 모델이 회귀분석과 차 별화되는 점이며 이러한 근거를 토대로 본 연구에서는 매개된 조절효과 모형을 구조방정식 모형 분석으로 검증하였고, $\mathrm{Yu}$ (2015a)와 Preacher, Rucker와 Hayes (2007)가 제안한 매개된 조 절효과 검증절차를 적용하였다. 즉, 먼저 매개효과와 조절효 과가 각각 통계적으로 유의미해야 하고 다음으로 두 모델이 결합된 매개된 조절효과를 분석하는 순서이다.

본 연구에서 연구문제와 개념적 연구모형 및 통계적 모형 은 다음과 같다.

\section{연구문제1}

어머니의 아동기 수용 경험과 아동의 정서조절 방식 관계에 서 감정코칭 반응은 매개효과가 나타나는가?

\section{연구문제2}

어머니의 아동기 수용 경험과 감정코칭 반응 간 관계에서 사 회적지지 수준은 조절효과가 나타나는가?

\section{연구문제3}

어머니의 아동기 수용 경험, 감정코칭 반응, 아동의 정서조절 
방식 관계에서 사회적 지지수준의 매개된 조절효과가 나타나 는가?

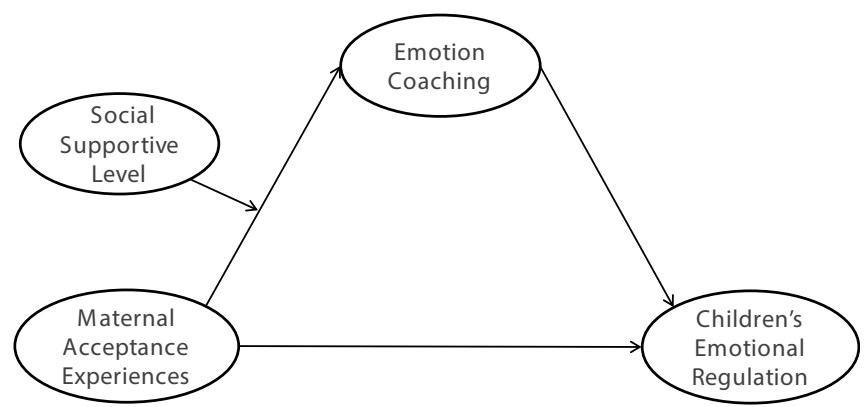

Figure 1. Conceptual model.

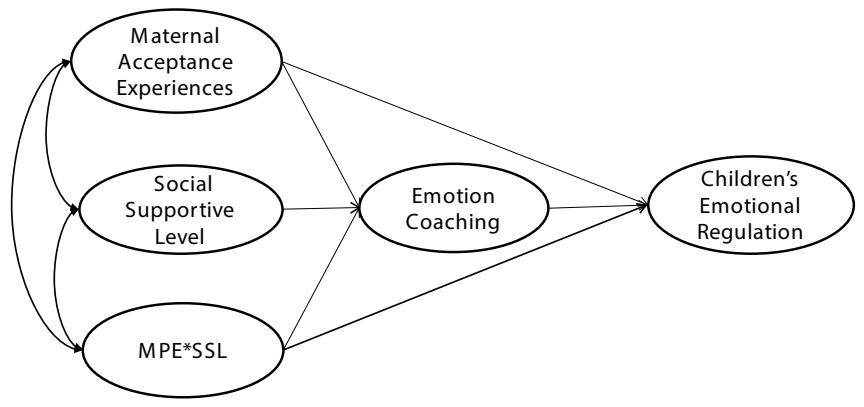

Figure 2. Statistical model.

\section{연구방법}

\section{연구대상}

본 연구는 초등학교 4-6학년 아동과 그들의 어머니를 연구대 상으로 선정하였다. 후기 아동기는 부모와의 관계를 통해 자 신의 정서를 발달시켜 사회적으로 기능하는 시기에 속하며, 아동의 정서발달 과정의 중요한 시점이다(Goleman, 1995). 즉, 자신이 시도하는 정서조절의 내적과정을 이해하고 변별 할 수 있는 능력이 시작되며 여러 가지 정서적 자극에 대한 표 현이나 전략이 안정되기 시작한다는 발달적 관점(O. B. Jeong, Jeong, \& Lim, 2007)을 고려하였다.

본 연구는 서울과 경기 지역에 소재한 4개 초등학교 4-6 학년 아동과 그들의 어머니 463 쌍이 참여하였다. 본 연구대 상의 특성을 살펴보면 아동의 경우, 성별은 여학생이 238 명 (51.5\%), 남학생이 224명(48.5\%)으로 나타났고 학년은 초등 4 학년 152명(32.9\%), 5학년 190명(41.1\%), 6학년 120명(26.0\%)
으로 나타났다. 다음으로 아동의 어머니 특성을 살펴보면 어 머니 연령은 40 세 미만이 148 명(32.0\%), 40 에서 50세 미만이 300 명(66.3\%), 50세 이상이 14명(1.7\%)으로 나타났고, 교육수 준은 고등학교 졸업이하가 227명(49.1\%)이었고, 대학교 졸업 이상은 158 명(34.1\%), 전문대학 졸업 68명(14.7\%), 중학교 졸 업 이하는 5명(1.1\%) 순으로 나타났다.

\section{연구도구}

\section{어머니의 아동기 수용 경험 척도}

아동기 원부모의 양육방식을 측정하기 위하여 Epstein (1983) 의 부모-또래 척도(Mother-Father-Peer Scale)를 Jeun (1996)이 수정한 척도로 사용하였다. 총 70 문항의 4 개의 하위요인으로 구성되어 있으나 본 연구에서는 아동기 부모에게 받은 수용 경험만을 측정하고자 수용 대 거부 차원(9문항)만을 활용하 였다. 예를 들면, "(내가 어렸을 때 나의 어머니/아버지는)나와 함께 있는 것을 즐거워 하셨다.", "어떤 일을 나와 함께 하시는 경우가 거의 없었다." 등의 문항으로 구성되어 있다.

본 척도는 점수가 높을수록 원부모에게 받은 수용 경험이 많은 것으로 해석하고, 점수가 낮을수록 지각된 거부 경험이 많은 것을 의미한다. 본 연구에서 산출한 각 하위요인별 신뢰 도(Cronbach's $\alpha$ ) 검증 결과는 원모의 수용 대 거부 차원 .85 , 원 부의 수용대 거부-차원 85 로 나타났다.

\section{어머니의 사회적지지 수준 척도}

어머니의 지각된 사회적지지를 측정하기 위하여 Park (1985) 이 개발하고 Yoon (1993)이 수정하여 타당화한 척도를 사용하 였다. 사회적 지지척도의 유형별로는 정서적 지지, 평가적 지 지, 정보적 지지, 물질적 지지 문항의 4 개 하위변인으로 구성 되어 있으나 본 연구에서는 어머니의 사회적 관계 안에서 지 지 수준을 살펴보고자 물질적 지지를 제외하고 3 개의 하위변 인에 대한 총 19항목을 사용하였고, Likert 5점 척도로 평가하 였다. 구체적으로 살펴보면, 정서적 지지는 "그는 내가 사랑 과 보살핌을 받고 있다고 느끼게 해준다.”, 평가적 지지의 경 우 “내가 잘했을 때 칭찬을 아끼지 않을 것이다.", 마지막으로 정보적 지지는 "내가 중요한 선택을 해야 할 때 충고와 조언을 해줄 것이다." 등의 문항으로 이루어져 있다.

또한, 본 연구에서는 배우자, 친구, 부모님으로 구분하여 측 정하도록 하였고 본 척도의 점수가 높을수록 배우자, 친구, 부 
모님에게 지각된 사회적지지 수준이 높은 것으로 해석한다. 본 연구에서 산출한 각 하위요인별 신뢰도(Cronbach's $\alpha$ ) 검증 결과는 배우자 지지 .98 , 친구 지지 .98 , 부모님 지지 .98 로 나 타났다.

\section{어머니의 감정코칭 반응 척도}

어머니의 감정코칭 반응을 측정하기 위해 $\mathrm{Oh}$ (2013)가 개발하 고 타당화한 아동의 부정적 정서표현에 대한 어머니 반응 척 도를 사용하였다. 본 척도는 총 21 문항이며 세 가지 하위요인 으로 구성되어 있으나, 본 연구의 목적에 부합하는 감정코칭 반응 유형(10문항)만을 활용하였다. 감정코칭 반응은 자녀의 부정적 정서표현에 대해 감정을 인정하며 수용하는 반응과 더 불어 아이가 스스로 문제를 해결하도록 이끌면서 행동에 한계 를 정해 주는 태도를 포함하는 내용으로 점수가 높을수록 어 머니가 감정코칭 반응을 많이 하는 것으로 해석한다. 문항으 로는 “나의 마음이 진정 될 때까지 기다려 주신다.", "내가 스 트레스를 풀 수 있는 방법을 제안해 주신다." 등이 있다. 본 연 구에서 산출한 신뢰도(Cronbach's $\alpha$ ) 검증 결과는 .90 으로 나 타났다.

\section{아동의 정서조절 방식 척도}

본 연구에서는 아동의 정서조절 방식을 측정하기 위하여 $\mathrm{Lim}$ (2001)이 Calkins (1994)의 정서조절 정의를 근거로 Eisenberg (1993)가 사용한 13 가지 아동의 정서조절 방식을 고려하여 요 인과 문항을 구성한 척도를 사용하였다. 총 29문항이며 4개의 하위요인(문제중심적 대처 및 지지추구, 감정발산, 공격적 표 현, 회피)의 점수가 높을수록 각각의 요인에 해당하는 정서조 절 방식을 많이 보이는 것으로 해석한다. 그러나 본 척도의 경 우 이론적 근거를 토대로 다양한 하위요인을 구성하고 전문가 를 활용한 내용타당도를 검증은 하였으나 통계적으로 요인구 조에 대한 적합성 검증을 거치지 않았다는 한계가 지적되었 고, 확인적 요인분석 결과 내적일치도에서 낮은 수치를 보이 는 문제점이 나타났다(Oh, 2015).

이를 보완하고자 본 연구에서 수집된 자료로 탐색적 요인 분석을 실시하였고, 요인의 수를 결정하기 위해 고유치 값 (eigen value), 스크리 도표(scree plot), 누적분산비율의 값을 고 려해 2개의 하위요인으로 구성되는 것이 적절하다고 판단하 였다. 또한, 요인적재량이 .50이하와 해석차원에서 다른 문항 과 어울리지 못하는 문항을 제외시키는 과정을 반복하여 총
14 문항을 선정하였다. 1 요인(6문항)은 원 척도의 문제중심적 대처 및 지지추구에 해당하는 문항들로 구성되어 있어서(예: "나는 공부하는 것에 대해 걱정이 있는 경우 그 걱정을 부모님 께 상의 드린다.”) 적응적 정서조절방식으로 명명하였고, 2요 인(8문항)의 경우 원 척도의 감정발산, 공격적 표현, 회피 요인 에 해당하는 문항들이란 점을 고려하여(예: "나는 부모님께서 내가 사달라고 하는 옷이나 장난감을 안사준신다고 하면 방문 을 쾅 닫거나 소리를 지르곤 한다.”, “나는 부모님이 잔소리를 하실 때 다른 생각을 하고 있거나 다른 곳을 쳐다보면서 듣는 척을 한다.”) 부적응적 정서조절방식으로 명명하였다. 본 연구 에서 산출한 각 하위요인별 신뢰도(Cronbach's $\alpha$ ) 검증 결과는 적응적 정서조절 방식은 .71 , 부적응적 정서조절 방식은 .80 으 로 나타났다. 이와 더불어 개념 신뢰도와 평균분산추출값 또 한 .73과 .63으로 높게 나타나 두 하위요인의 내적일치도가 높 음을 알 수 있다.

\section{연구절차}

본 조사연구는 각 학교에 우편발송하거나 직접 방문하는 방법 으로 실시하였다. 설문지는 학생용, 부모용으로 구분하였고. 부모용 설문지에는 본 연구의 목적과 동의서를 첨부하여 아동 을 대상으로 하는 연구에 대한 보호자 동의를 받았다. 교사에 게는 연구자가 검사의 구성과 실시절차에 대하여 설명하였고 교사가 사전에 안내문을 숙지하도록 하여 설문 실시에 어려움 이 없도록 하였다. 총 480 부를 회수하였는데, 보호자 동의가 없거나 불성실한 질문지를 제외한 463 부를 자료 분석에 활용 하였다.

\section{자료분석}

본 연구에서 수집된 자료는 SPSS 17.0 (SPSS Inc., Chicago, $\mathrm{IL})$ 을 이용해 기술통계 분석과 신뢰도 검증을 실시하였고, AMOS 20.0 (IBM Co., Armonk, NY)을 이용하여 관련 변인들 간의 구조방정식 모형을 분석하였다. 즉, 매개효과 검증, 조 절효과 검증, 매개된 조절효과 검증 모두 구조방정식 모형으 로 분석하였다. 이 때 모형의 적합도를 평가하기 위해서 적합 도 지수(TLI, IFI, CFI, RMSEA)를 살펴보았다. TLI, CFI, IFI, $\mathrm{GFI}$ 의 경우 .90이상이면 좋은 적합도를 보인다고 할 수 있고 RMSEA의 경우 $.08, .09$ 이하는 좋은 적합도로 해석한다(Hong, 2000).

또한, 경로의 효과성을 분해하고 매개효과의 유의성을 평 
가하기 위해 부트스트래핑(bootstrapping)방법을 활용하여 분 석하였다. 매개효과의 통계적 유의성 검증에 이론적 분포가 아닌 경험적 분포를 사용하는 방법의 제안(Preacher \& Selig, 2012)과, 정규분포를 가정하지 않으면서 보다 정확한 신뢰구 간을 산출하는 부트스트래핑(bootstrapping)방법이 매개효과 의 유의도 검증에 적합하다는 제언(MacKinnon et al., 2002; Shrout \& Bloger, 2002)을 근거로 분석하였다.

\section{연구결과}

측정모형의 타당도와 구조모형 분석에 앞서 변인들의 평균과 표준편차, 왜도와 첨도 값을 제시하고 변인들 간의 상관분석 을 실시하였다. 그 결과는 Table 1에 제시한 바와 같다.

\section{측정모형의 타당도}

측정모형의 타당도는 구성개념이 관측변수에 의해서 얼마나 잘 측정되었는지를 나타낸다. 이를 검증하는 방법으로 잠재변 수를 측정하는 관측변수들의 일치성에 대한 집중타당성과 잠 재변인들이 동일한 개념이 아닌 독립된 개념을 나타내고 있 음을 검증하기 위한 판별타당성이 있다. 본 연구에서는 이러 한 타당성들의 검증을 위해서 확인적 요인분석을 실시하였고 최우도 추정법(Maximum Likelihood Estimation [MLE])을 적용 하였다. 확인적 요인분석모델의 적합도는 $\chi^{2}$ 값은 $117.107(d f=$ 26, $p=.000$ ), TLI .90, IFI .94, CFI .94, GFI .95, RMSEA .08로
모든 값이 양호하게 나타났다.

또한, 잠재변수와 측정변수를 설정할 때 전 문항을 단일항 목으로 합산하는 모델과 문항묶음을 통해 문항의 수를 조정 한 모델의 장단점을 고려한 연구자의 합리적 판단이 필요하다 (J. Lee \& Kim, 2016; Yu, 2014, 2015b). 본 연구에서는 모델의 경제성을 고려해 문항묶음을 통한 측정변인을 설정하였고 결 과는 Table 2에 제시한 바와 같다.

\section{집중타당성(Convergent validity)}

집중타당성은 잠재변수를 측정하는 관측변수들의 일치성에 대한 내용이며, 이를 평가하는 방법으로는 표준화 요인부하량 과 유의성, 평균분산추출값(Average Variance Extracted [AVE]), 개념 신뢰도(Construct Reliability [CR]) 등이 있다. 요인부하량 은 최소 .50 이상이 되어야 하고 .70 이상이면 바람직하다고 할 수 있다. 또한, CR과 AVE가 높다는 것은 해당하는 요인에 대 한 측정문항들의 내적일치도가 높다는 것을 의미하며, 일반적 으로 $\mathrm{CR}$ 는 .70 이상, $\mathrm{AVE} .50$ 이상이면 만족스러울 만한 집중 타당도를 나타내는 것으로 보고한다(G. S. Kim, 2010).

본 연구에서 확인적 요인분석을 통한 요인부하량과 유의성 검증, $\mathrm{CR}$ 과 $\mathrm{AVE}$ 를 구하는 공식으로 계산한 결과를 Table 2에 제시하였다. 구체적으로 살펴보면, $\mathrm{CR}$ 은 어머니의 아동기경 험 .71, 사회적지지 수준 .70, 어머니의 감정코칭 반응 .75, 아동 의 정서조절방식 .73으로 높게 나타났고, AVE의 경우 어머니의 아동기경험 .56 , 사회적지지 수준 .44 , 어머니의 감정코칭 반응 .61 , 아동의 정서조절방식 .63으로 높게 나타났다. 단. 사회적

Table 1

Correlations Among Six-Variables and Descriptive Statistics Values

\begin{tabular}{|c|c|c|c|c|c|c|}
\hline & 1 & 2 & 3 & 4 & 5 & 6 \\
\hline 1. Maternal acceptance experience_mother & - & & & & & \\
\hline 2. Maternal acceptance experience_father & $.590^{* * *}$ & - & & & & \\
\hline 4. Emotion-coaching reaction & $.174^{* * *}$ & $.097^{*}$ & $.189^{* * *}$ & - & & \\
\hline 5. Adaptive emotion regulation & $.151^{* * *}$ & $.113^{*}$ & $.138^{* *}$ & $.540^{* * *}$ & - & \\
\hline$M$ & 34.48 & 32.73 & 75.20 & 35.90 & 16.11 & 15.25 \\
\hline$S D$ & 6.84 & 8.66 & 19.37 & 8.09 & 3.45 & 4.34 \\
\hline Skewness & -1.24 & -1.77 & -1.68 & -.35 & -.33 & .29 \\
\hline Kurtosis & 3.19 & 3.24 & 3.50 & -.09 & -.00 & .32 \\
\hline
\end{tabular}

Note. $N=463$.

${ }^{*} p<.05 .{ }^{* *} p<.01 .{ }^{* * *} p<.001$. 
Table 2

Convergent Validity

\begin{tabular}{|c|c|c|c|c|c|}
\hline Latent variables & Measurement variables & $\beta$ & $t$-value & CR & AVE \\
\hline \multirow[t]{2}{*}{ Maternal acceptance experiences } & MAE_mother & .621 & $11.231^{* * *}$ & .712 & .563 \\
\hline & MAE_father & .950 & Fix & & \\
\hline & Friend & .726 & $14.486^{* * *}$ & & \\
\hline & Parents & .813 & Fix & & \\
\hline \multirow[t]{2}{*}{ Emotion coaching } & Emotion coaching_1 & .877 & Fix & .754 & .606 \\
\hline & Emotion coaching_2 & .879 & $16.820^{* * *}$ & & \\
\hline Children's emotion regulation & Maladaptive emotion regulation & .360 & $3.886^{* * *}$ & .734 & .634 \\
\hline
\end{tabular}

Note. $\mathrm{MAE}=$ maternal acceptance experience; $\mathrm{CR}=$ construct reliability; $\mathrm{AVE}=$ average variance extracted. ${ }^{* * *} p<.001$.

Table 3

Fit Indices of Observed Models

\begin{tabular}{lcccccccc}
\hline & \multicolumn{1}{c}{$\chi^{2}$} & $d f$ & $\chi^{2} / d f$ & TLI & IFI & CFI & GFI & RMSEA \\
\hline 1 & 5.43 & 6 & .90 & .99 & .99 & .99 & .99 & .00 \\
2 & 100.11 & 15 & 6.67 & .88 & .93 & .93 & .95 & .09 \\
3 & 117.10 & 26 & 4.50 & .90 & .94 & .94 & .95 & .08 \\
\hline
\end{tabular}

Note. $N=463.1$ = mediated model; $2=$ moderation model; $3=$ mediated moderation model.

지지수준의 AVE가 .44로 기준치에 다소 미치지 못하는 결과이 나 요인부하량이 기준치 이상이고 개념 신뢰도 역시 .70이상으 로 높게 나타나 집중타당성에 문제가 없는 것으로 판단하였다. 또한, 부적응적 정서조절 방식의 경우 요인부하량이 .360으로 기준치에 부적합하게 나타났으나 측정문항들의 내적일치도를 알아보는 개념 신뢰도와 AVE가 높은 편이며 Cronbach's $\alpha$ 검증 결과 .80으로 높게 나타나 삭제 없이 분석에 활용하였다.

\section{판별타당도(Discriminant validity)}

판별타당도는 잠재변인들이 동일한 개념이 아닌 독립된 개념 을 나타내고 있음을 검증하기 위한 것으로 판별타당도를 검토 하는 방법으로 본 연구에서는 자유모델과 제약모델 간 $\chi^{2}$ 값의 차이를 비교하는 분석을 통해 살펴보았다. 이는 구성개념 간 상관을 1 로 고정한 모델과 그렇지 않은 자유모델 간 $\chi^{2}$ 차이분 석을 실시하여 두 모델 간 $\chi^{2}$ 에 유의한 차이가 있는지 없는지 를 비교하는 방법이다(Yu, 2012). 분석 결과, 모든 쌍에서 자유
모델과 제약모델 간 차이가 유의하게 나타나 $\left(\Delta \chi^{2}=3.84[d f=\right.$ $1]$, 이상일 때 통계적으로 유의) 구성 개념 간 판별타당성이 있 는 것으로 나타났다.

\section{구조모형 분석}

본 연구에서는 $\mathrm{Yu}$ (2015a)와 Preacher 등(2007)이 제안한 매개 된 조절효과 검증절차를 따라 매개모형, 조절모형, 매개된 조 절모형 순서로 구조방정식 모형을 분석하였고, 각 연구모형의 모델 적합도 지수는 다음과 같다.

\section{어머니의 아동기 수용 경험과 아동의 정서조절 방식에서 감정코칭 반응의 매개효과}

어머니의 아동기 수용 경험, 아동의 정서조절 방식, 감정코칭 반응의 구조방정식 모형 분석 결과를 Table 4, Figure 3에 제시 하였다. 또한 직접효과, 간접효과 및 총 효과를 알아보았고 간 
접효과의 유의성을 알아보기 위해 bootstrapping방법이 사용되 었으며 그 결과는 Table 5에 제시한 바와 같다.

이를 구체적으로 살펴보면, Table 4에 제시한 바와 같이 어 머니의 아동기 수용 경험은 아동의 정서조절 방식에 직접적으 로 영향을 미치지 않았다. 반면, 아동기 수용 경험은 감정코칭 반응에 $(\beta=.186, p<.001)$, 감정코칭 반응은 아동의 정서조절 방식에 $(\beta=.727, p<.001)$ 유의한 영향을 미쳤다.

또한, 간접효과의 유의성을 알아보기 위해 부트스트래핑 방법(bootstrapping)을 사용하였는데, 이 방법은 신뢰구간을 제 시하고 그 구간이 0 을 포함하지 않으면 간접효과가 통계적으 로 유의함을 의미한다(Shrout \& Bolger, 2002). Table 5에 따르 면, 아동기 수용 경험 $(\beta=.070, p<.01$, bias-corrected $\mathrm{CI}=.068$ - .208)이 감정코칭 반응을 거쳐 아동의 정서조절 방식으로 가 는 매개효과가 유의한 것으로 나타났다. 즉, 아동기 수용 경험 은 감정코칭 반응을 매개로 아동의 정서조절 방식에 영향을 미치는 완전매개모형을 보이는 것으로 나타났다.

\section{어머니의 아동기 수용 경험과 감정코칭 반응에 서 사회적지지 수준의 조절효과}

어머니의 아동기 수용 경험과 감정코칭 반응에서 사회적지지 수준의 조절효과를 분석하기 위해서는 우선, 예언변인과 조절 변인의 상호작용항을 만드는 과정이 필요하다. 이 과정에서 상호작용항의 다중공선성을 감소시키기 위한 방법으로 어머 니의 아동기 수용 경험과 사회적지지 수준 변인을 표준점수로 변환시킨 후 곱항을 만들어 구조방정식 모형을 분석하였다. 감정코칭 반응에 대한 어머니의 아동기 수용 경험과 사회적 지지 수준의 상호작용 효과에 대한 결과는 Table 6, Figure 4에 제시하였다. 어머니의 사회적지지 수준은 감정코칭반응 $(\beta=$ $.537, p<.001)$ 에 유의한 영향을 미쳤다. 이는 감정코칭 반응에 대한 아동기 수용 경험과 사회적지지 수준을 동시에 고려했을 때 사회적지지가 보다 영향력이 크다는 것을 의미한다. 또한, 아동기 수용 경험과 사회적지지 수준의 상호작용 변인은 감

Table 4

Path Estimate of Latent Variables

\begin{tabular}{|c|c|c|c|c|c|c|}
\hline \multicolumn{2}{|c|}{ Path of Latent Variables } & \multirow{2}{*}{$\begin{array}{c}B \\
.023\end{array}$} & \multirow{2}{*}{$\begin{array}{c}\beta \\
.044\end{array}$} & \multirow{2}{*}{$\begin{array}{c}S E \\
.027\end{array}$} & \multirow{2}{*}{$\begin{array}{r}t \text {-value } \\
.862\end{array}$} & \multirow{2}{*}{$\begin{array}{c}p \\
.389\end{array}$} \\
\hline Maternal acceptance experiences & $\rightarrow \quad$ Children's emotion regulation & & & & & \\
\hline Maternal acceptance experiences & $\rightarrow \quad$ Emotion coaching reaction & .132 & .186 & .037 & 3.580 & .000 \\
\hline Emotion coaching reaction & $\rightarrow$ Children's emotion regulation & .534 & .727 & .043 & 12.311 & .000 \\
\hline
\end{tabular}

Table 5

Direct, Indirect, Total Effects, and Significant Validation of Indirect

\begin{tabular}{|c|c|c|c|c|c|c|c|}
\hline \multirow[b]{2}{*}{ Path of latent variables } & \multirow[b]{2}{*}{ Direct effects } & \multirow[b]{2}{*}{ Indirect effects } & \multirow[b]{2}{*}{ Total effects } & \multirow[b]{2}{*}{$S E$} & \multicolumn{2}{|c|}{ BC $95 \%$ CI } & \multirow[b]{2}{*}{$p$} \\
\hline & & & & & Lower & Upper & \\
\hline $\begin{array}{l}\text { Maternal acceptance experiences } \\
\quad \rightarrow \text { Emotion coaching } \\
\quad \rightarrow \text { Children's emotion regulation }\end{array}$ & .044 & .135 & .179 & .071 & .068 & .208 & .002 \\
\hline
\end{tabular}

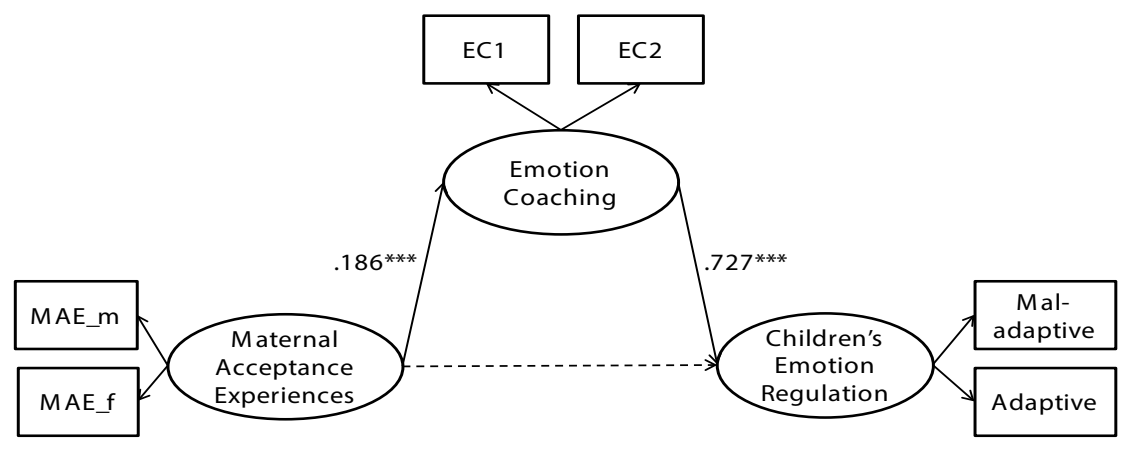

Figure 3. Mediated model.

${ }^{* * *} p<.001$. 
정코칭 반응 $(\beta=.390, p<.05)$ 을 유의미하게 예측하는 것으로 나타났다. 즉, 조절효과가 통계적으로 유의미하게 나타남을 의미한다.

조절효과를 해석하기 위해 Aiken과 West (1991)가 제시한 바와 같이, 조절변인의 평균값과 \pm 표준편차 값에서 아동기 수 용 경험이 어머니의 감정코칭에 미치는 영향을 그래프를 통해
서 확인해 보았다. 이에 대한 수치와 그래프는 Table 7, Figure 5 에 제시하였다.

Figure 5에서와 같이 어머니가 아동기 원부모에게 받은 양 육경험을 수용적으로 지각하고 사회적지지 수준이 높을 경우 $(+1 S D)$ 자녀에게 감정코칭 반응을 많이 하며, 사회적지지 수 준이 낮을 경우 $(-1 S D)$, 감정코칭 반응을 보다 적게 하는 것으

Table 6

Path Estimate of Latent Variables

\begin{tabular}{|c|c|c|c|c|c|c|}
\hline \multicolumn{2}{|r|}{ Path of Latent Variables } & $B$ & $\beta$ & $S E$ & $t$-value & $p$ \\
\hline Maternal acceptance experiences & $\rightarrow$ Emotion coaching reaction & -.018 & -.034 & .054 & -.334 & .739 \\
\hline Social supportive level & $\rightarrow$ Emotion coaching reaction & .153 & .537 & .045 & 3.387 & .000 \\
\hline Maternal acceptance experiences $\times$ & Social supportive level $\rightarrow$ Emotion coaching reaction & 1.717 & .390 & .822 & 2.090 & .037 \\
\hline
\end{tabular}

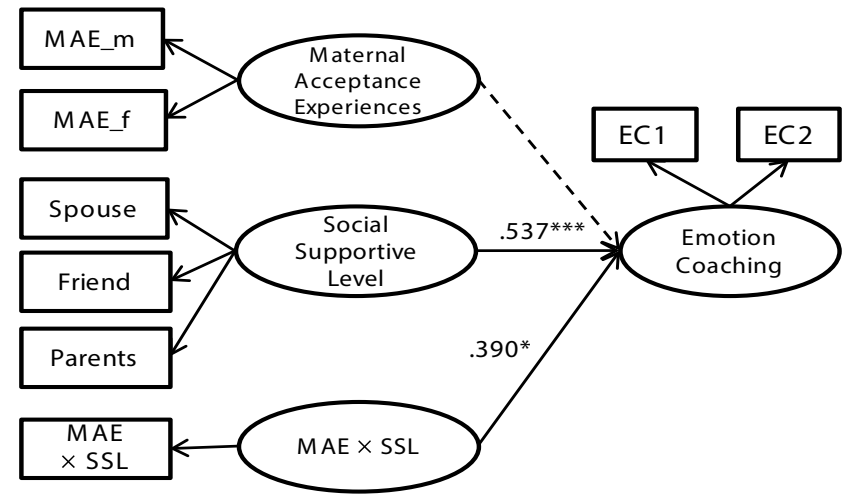

Figure 4. Moderation model.

${ }^{*} p<.05 .{ }^{* * *} p<.001$.

Table 7

Mean and Standard Deviation of Variables

\begin{tabular}{ccccc}
\hline Variable & $N$ & Minimum value & Maximum value & $M(S D)$ \\
\hline Social support level & 463 & 45 & 285 & $222.97(45.74)$ \\
\hline
\end{tabular}

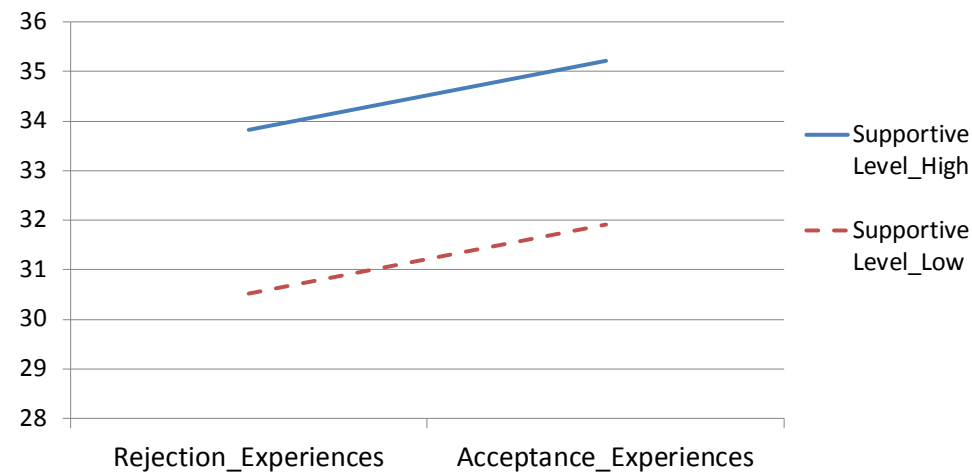

Figure 5. Interaction effect between maternal-acceptance experience and social-supportive level. 
로 나타났다. 또한, 어머니가 아동기 경험을 거부적으로 지각 하더라도 사회적지지 수준이 높을 경우 $(+1 S D)$ 에는 감정코칭 반응에 미치는 효과가 커짐을 알 수 있다. 다음으로, 조절변 인이 평균값과 \pm 1 표준편차 값을 가질 경우 아동기 수용 경험 이 감정코칭 반응에 미치는 효과인 단순기울기의 통계적 유 의성을 확인한 결과 사회적지지 수준이 높은 경우(+1SD), $B=$ $2.339, S D=.939(t=2.490, p<.01)$ 로 나타났다. 사회적지지 수준이 낮은 경우(-1SD)는 $B=1.371, S D=.375(t=3.652, p<$ .001) 로 나타나 단순기울기 모두 통계적으로 유의함을 알 수 있다.

따라서 사회적지지 수준은 어머니의 아동기 양육경험이 감 정코칭에 미치는 영향을 완충하는 효과를 보임을 확인할 수 있었다. 이는 어릴 적 원부모와의 양육경험이 거부적이었다고 할지라도 이후 사회적지지가 어떠한 수준으로 변화되느냐에 따라 어머니의 감정코칭 반응에 미치는 부정적 영향력이 감소 될 수 있음을 보여준다.
어머니의 아동기 수용 경험, 사회적 지지와 감정코 칭 반응이 아동의 정서조절 방식에 미치는 영향: 매개된 조절효과(mediated moderation effect)

본 연구는 매개된 조절효과의 분석 절차에 따라 연구문제 1,2 에서 매개효과와 조절효과가 유의함을 검증하였다. 다음으로 이를 결합한 매개된 조절효과를 분석하였다. 다시 말해, 어머 니의 아동기 수용 경험, 사회적지지 수준, 아동기 수용 경험과 사회적지지 수준의 상호작용 변수가 어머니의 감정코칭 반응 을 통해 아동의 정서조절방식에 미치는 직접효과, 간접효과, 총 효과를 알아보았고, 결과는 Table 8, Table 9 과 Figure 6에 제 시하였다.

구체적으로 살펴보면, 어머니의 사회적지지 수준 $(\beta=.513$, $p<.01)$ 과 아동기 수용 경험과 사회적지지 수준의 상호작용 변수 $(\beta=.398, p<.05)$ 는 감정코칭 반응을 유의미하게 예측하 는 것으로 나타났으며, 이러한 감정코칭 반응은 아동의 정서

Table 8

Path Estimate of Latent Variables

\begin{tabular}{lrrrrr}
\hline \multicolumn{1}{c}{ Path of Latent Variables } & $B$ & $\beta$ & $S E$ & $t$-value & $p$ \\
\hline Maternal acceptance experience $\rightarrow$ Emotion coaching reaction & .007 & .016 & .051 & .147 & .883 \\
Social supportive level $\rightarrow$ Emotion coaching reaction & .126 & .513 & .042 & 3.025 & .002 \\
Maternal acceptance experiences $\times$ Social support level $\rightarrow$ Emotion coaching reaction & 1.500 & .398 & .752 & 1.993 & .046 \\
Emotion coaching reaction $\rightarrow$ Children's emotion regulation & .543 & .747 & .050 & 10.895 & .000 \\
Social supportive leve $\rightarrow$ Children's emotion regulation & -.019 & -.108 & .027 & -.699 & .485 \\
Maternal acceptance experiences $\times$ Social support level $\rightarrow$ Children's emotion regulation & -.251 & -.092 & .479 & -.523 & .601 \\
Maternal acceptance experiences $\rightarrow$ Children's emotion regulation & .024 & .073 & .033 & .731 & .465 \\
\hline
\end{tabular}

Table 9

Direct, Indirect, Total Effects, and Significant Validation of Indirect

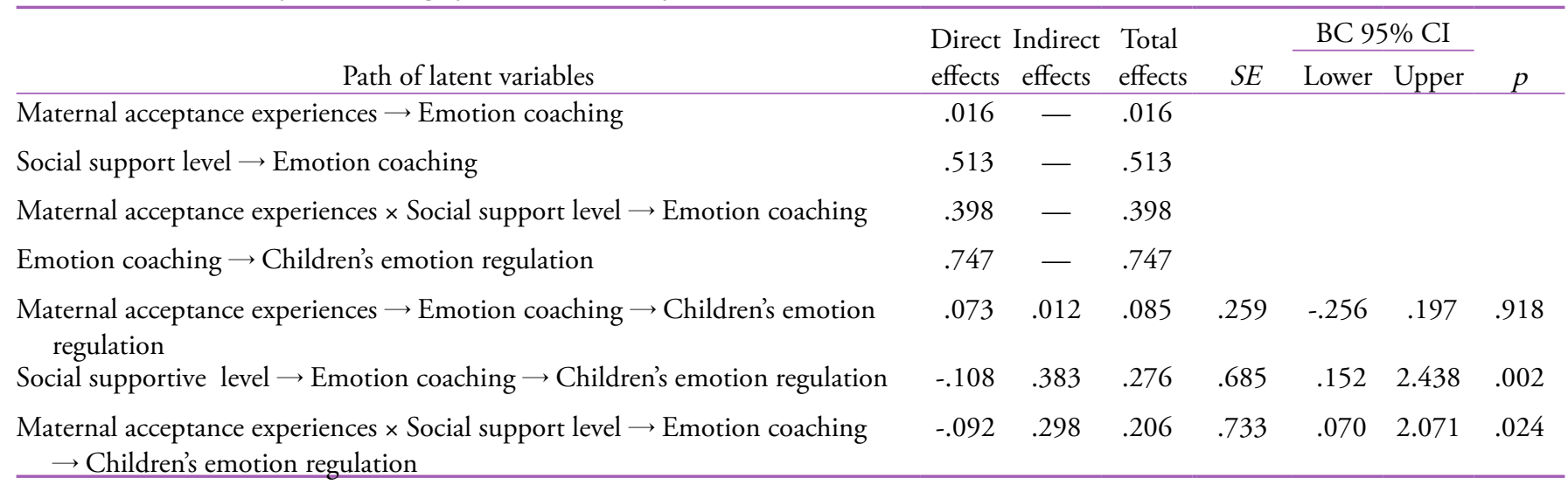




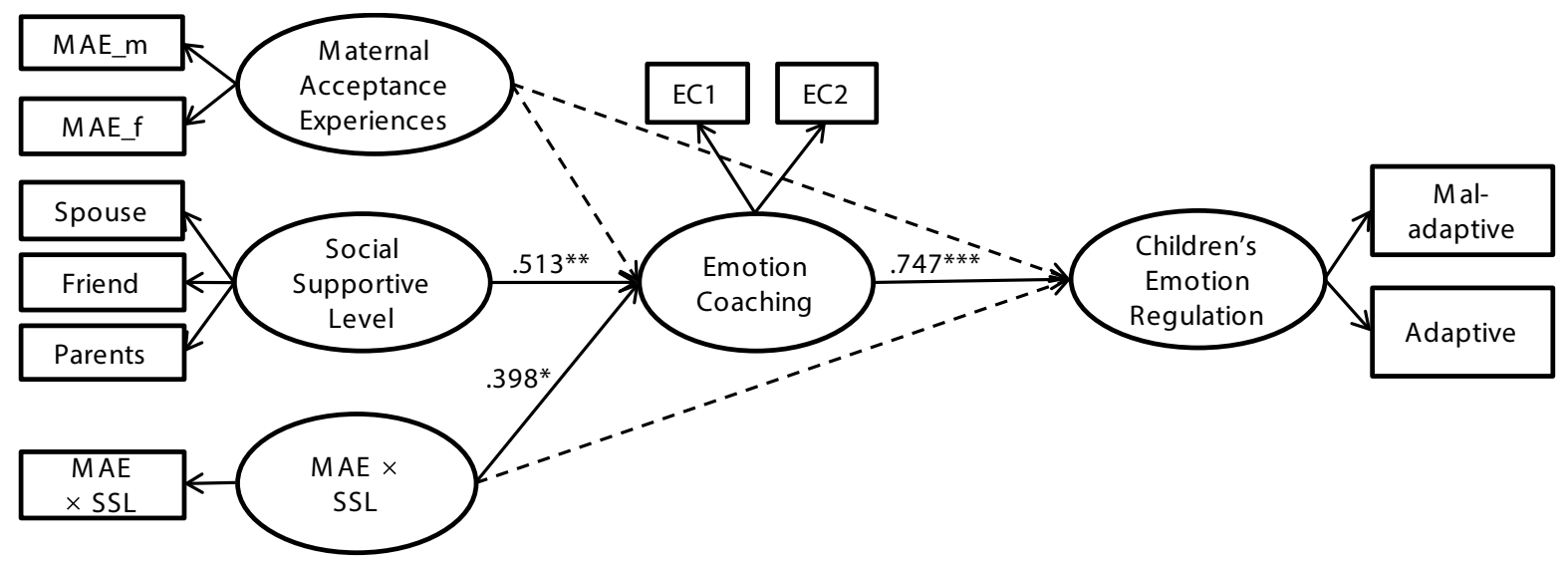

Figure 6. Mediated-moderation model.

${ }^{*} p<.05 .{ }^{* *} p<.01 .{ }^{* * *} p<.001$.

조절방식 $(\beta=.747, p<.001)$ 에 유의미한 직접효과를 보였다. 또한, 간접효과의 유의성을 알아보기 위해 부트스트래핑 방 법(bootstrapping)을 사용하였다. Table 9에 따르면, 어머니의 사회적지지 수준(.383, $p<.01$, bias-corrected CI = .152-2.438) 이 감정코칭 반응을 거쳐 아동의 정서조절방식으로 가는 간 접효과가 통계적으로 유의하였다. 아동기 수용 경험과 사회 적지지 수준의 상호작용 변인(.298, $p<.05$, bias-corrected CI = .070-2.071) 또한 감정코칭 반응을 매개로 하여 아동의 정서조 절방식으로 가는 경로에서 간접효과의 유의성이 검증되었다. 즉, 어머니의 사회적지지 수준 그리고 아동기 수용 경험과 사 회적지지 수준의 상호작용 변수는 감정코칭 반응을 매개로 아 동의 정서조절 방식에 영향을 미치는 완전매개모형을 보이는 것으로 나타났다.

\section{논의 및 결론}

본 연구에서는 어머니의 아동기 수용 경험과 자녀의 정서조절 방식 관계에서 어머니의 감정코칭 반응이 매개할 것이라는 가 설과 사회적지지 수준의 조절효과를 확인하는 연구모형을 설 정하였고 이러한 매개된 조절모형을 구조방정식 모델분석으 로 검증하였다.

연구모델의 분석 결과 첫째, 아동기 수용 경험과 아동의 정 서조절 방식 간 관계에서 감정코칭 반응의 매개효과가 유의 하게 나타났다. 즉, 어머니가 원부모의 양육방식을 수용적으 로 지각할수록 자녀에게 감정코칭 반응을 많이 하게 되고 이 는 아동의 적응적 정서조절 방식에 영향을 미치고 있음을 의
미한다. 이러한 결과는 어머니의 아동기 경험이 어머니의 정 서조절 방식 및 정서반응 태도에 영향을 미치고, 이는 자녀의 정서능력과 밀접한 관련이 있는 것으로 나타난 선행연구(E.K. Kim \& Song, 2009)와 일치한다. 또한, 어머니의 아동기 경 험과 애착표상이 양육행동을 매개로 아동의 정서, 사회성 발 달에 영향을 미친다는 연구결과들(Chae \& Lee, 2009; M. K. Jeong \& Kim, 2003; M.-S. Lee, Lee, Park, \& Shin, 2008)과도 부 분적으로 맥락을 같이한다. 이러한 관점에서 관련 선행연구의 경험적 증거와 본 연구결과를 고려해 볼 때, 아동기 원부모와 의 관계는 부모가 되어 자녀의 부정적 정서표현에 대한 감정 코칭 반응을 어떻게 하게 되느냐에 영향을 주고 이는 아동의 정서조절 능력으로 이어짐을 시사한다. Eisenberg 등(1998)의 정서사회화 발견적 모델 또한, 본 연구결과를 부분적으로 뒷 받침한다.

둘째, 아동기 수용 경험과 감정코칭 반응의 관계는 사회적 지지 수준에 의해 조절되며, 마지막으로 아동기 수용 경험과 아동의 정서조절 방식 간 관계에서 감정코칭 반응의 매개효과 는 사회적지지 수준에 영향을 받는다는 매개된 조절효과가 유 의한 것으로 나타났다. 먼저, 아동기 수용 경험과 감정코칭 반 응의 관계에서 사회적지지 수준의 조절효과를 살펴보면, 지각 된 아동기 경험이 수용적이었고 이후의 사회적지지 수준 또 한 높을수록 아동의 부정적 정서표현에 대해 감정코칭 반응 을 많이 하는 것으로 나타났다. 이는 어린 시절 원부모와 긍정 적인 상호작용을 경험한 부모는 자신을 원부모와 동일시하 는 과정을 통해 이후 자녀와의 관계에서 건강한 방식으로 양 육에 참여한다는 선행연구 결과(Cowan et al., 1996; Y. J. Jeong, 2008; Kwon, 2011)와 일맥상통한다. 뿐만 아니라 배우자의 지 
지가 높을수록 어머니는 자녀를 합리적이고 애정적이며 성취 지향적으로 양육하게 되며, 자녀에 대해 적극적인 참여와 일 관성 있는 규제를 가하는 동시에 권위주의적인 통제는 적게 하는 것으로 나타난 연구결과(J. S. Lee \& Chung, 2007; Moon, 2001)와 맥락을 같이한다. 반면, 원부모와의 관계에서 거부감 을 경험했던 어머니이더라도 이후 배우자 및 친구 등에게 사 회적지지 경험이 많다면, 감정코칭 반응에 긍정적인 영향을 미치는 것으로 나타났다. 이는 아동기 원부모의 양육방식이 부정적이더라도 이후의 높은 사회적지지 수준을 경험한다면, 부정적 영향이 완화되어 본인 자녀의 정서표현에 대한 감정코 칭 반응은 증진 될 수 있음을 의미한다. 이러한 결과를 근거로 어머니의 감정코칭 반응의 촉진을 돕기 위해서는 어머니의 아 동기 원부모와의 관계 뿐만 아니라 이후 사회적지지 체계에서 지각된 수준을 함께 고려해야 하며, 특히 어머니의 지각된 사 회적지지 수준이 중요한 조절변수로서 역할을 하고 있음을 알 수 있다. 거부적이고 방임적 아동기를 경험한 부모들이 자신 의 아이들에겐 반대의 양육방식을 보이려 노력한다고 보고된 연구(Kwon, 2011)와도 부분적으로 일치하는 결과라고 볼 수 있다. 다시 말해, 어릴 적 원부모와의 관계에서 상처를 받았고 이러한 경험으로 부정적인 양육태도가 내면화되었지만 아동 기 이후의 환경적인 상황, 특히 중요한 타인으로부터 수용 받 는 지속적인 경험은 부모역할에 대한 높은 자신감과 만족감으 로 이어질 가능성이 높겠다. 이는 자녀의 부정적 정서를 수용 하고 지지해 줄 수 있는 태도에 영향을 준 것으로 추론해 볼 수 있겠다.

다음으로, 아동기 수용 경험, 사회적지지 수준 그리고 아동 기 수용 경험과 사회적지지 수준의 상호작용 변수가 아동의 정서조절방식에 미치는 영향에서 감정코칭 반응이 매개변수 로 투입된 조절된 매개효과가 유의한 것으로 나타났다. 어머 니의 아동기 양육경험과 아동의 정서조절방식 간 관계에 대한 감정코칭 반응의 매개효과가 어머니의 사회적 지지수준에 따 라 다르게 나타남을 알 수 있다. 이와 같은 결과는 어머니가 원 부모와 관계에서 거부 경험을 많이 경험하게 되면 자신의 자 녀에게 감정코칭 반응을 덜 보이게 될 수 있지만 아동기 이후 친구, 배우자 등의 높은 사회적 지지로 인해 완화되고 자녀에 게 감정코칭 반응을 어느 정도 할 수 있게 되기 때문에 아동의 정서조절방식에도 긍정적 영향을 줄 수 있음을 의미한다. 이 는 애착이론과 대상관계이론에서 생애초기의 부모와의 관계 경험으로 인해 형성되는 내적표상의 안정성을 강조하기도 하 지만 이후 건강하고 긍정적인 대상과 경험하면서 변형될 수 있음을 언급한 내용이 본 결과를 부분적으로 뒷받침해준다.
특히, 주목할 만한 연구결과는 아동기 원부모의 수용 경험 과 감정코칭 간 관계이다. 첫 번째 매개효과 검증에서는 두 변 인의 관련성이 통계적으로 유의하게 나타났지만, 조절된 매개 효과 검증에서는 아동기 수용 경험에 대한 영향력이 상쇄되어 감정코칭 반응과 아동의 정서조절 방식으로 이어지는 매개모 형은 간접효과가 유의미하게 나타나지 않았다. 이는 사회적지 지 수준의 조절변인이 보다 강력한 영향을 미치고 있음을 의 미한다. 사회적 지지감은 스트레스의 부정적인 영향을 감소시 키는 보호요인으로써 작용할 뿐만 아니라(Choi \& Kim, 2012), 사회적 지지를 높게 지각할수록 적응적 정서조절능력이 증진 됨을 밝힌 선행연구들(J.-Y. Lee \& Choi, 2012; Shin, 2014)을 고 려해볼 때, 어머니가 가족과 친구로부터의 지지감은 양육스트 레스를 줄이고 어머니의 정서조절과도 상호작용하여 자녀의 부정적 정서표현에 대한 감정코칭 반응에 긍정적 영향을 미치 고 있는 것으로 논의해 볼 수 있겠다.

요컨대, 아동기 원부모에게 받은 수용 경험이 감정코칭 반 응에 미치는 영향력의 정도는 사회적지지 수준에 의해 조절되 며, 아동기 수용 경험과 사회적지지 수준의 상호작용은 감정 코칭 반응을 매개로 아동의 정서조절방식에 영향을 주는 것으 로 나타난 결과는 어머니의 감정코칭 반응이 아동의 정서조절 에 있어서 중요한 요인임을 밝혔다. 또한, 이에 영향을 미치는 어머니의 아동기 원부모와 경험은 이후의 사회적지지 수준에 따라 차이를 보일 수 있음을 알 수 있다. 즉, 사회적 지지라는 환경적 보호요인을 강화하여 정서관련 양육행동에 미치는 영 향력을 완충할 수 있는 가능성에 주목해야 할 것이다. 본 연구 는 아동의 정서조절 방식에 영향을 주는 어머니의 아동기 수 용 경험과 사회적지지 수준, 감정코칭 반응에 대한 관련성을 경험적으로 검증하였고, 최근 정서에 초점을 두고 있는 부모 교육과 상담을 위한 개입방안의 근거를 제공할 수 있다는 점 에서 의의가 있다. 뿐만 아니라 정서관련 양육행동에 대한 부 모교육 프로그램을 개발하는데 필요한 기초자료로 기여할 수 있을 것으로 기대된다.

상기한 결과와 논의를 토대로 본 연구에서는 제한점과 후 속연구를 위해 다음과 같이 제안하고자 한다. 첫째, 양육행동 이나 공감행동에 있어서 자녀의 발달에 영향을 미치는 요인이 실제 객관적인 사실보다는 자녀의 주관적 경험이 중요하다는 선행연구(Trumpeter, Watson, O'leary, \& Weathington, 2008)를 근거로 자기보고식 질문지를 사용하였지만, 주관성을 배제하 는데 한계점이 있다. 보다 객관적으로 측정하기 위해서는 전 문가의 관찰 등을 통한 다양한 측정방법이 필요하다. 또한, 선 행연구에서 아동의 정서조절방식 척도의 제한점을 고려하여 
본 연구에서는 수집된 데이터로 탐색적 요인분석 과정을 통해 선별된 문항들을 분석에 활용하였다. 이는 보다 정확한 타당 도 검증에 있어서는 제한점이 있으므로 추후 연구에서 타당도 재검증이 필요할 것으로 여겨진다. 마지막으로, 본 연구에서 사용한 모든 변인들은 1 회의 설문조사를 통해 측정한 횡단자 료이다. 즉, 변수 간 인과성을 검증하는데 한계가 있고 이를 보 완하기 위해서는 일정한 시간적 간격과 변화를 가정한 종단연 구를 통해 변인 간 관계를 재검증할 필요성이 있다.

\section{Notes}

This article was presented at the 2016 Annual Spring Conference of the Korean Association of Child Studies.

\section{Conflict of Interest}

No potential conflict of interest relevant to this article was reported.

\section{References}

\section{In English}

Aiken, L. S., \& West, S. G. (1991). Multiple regression: Testing and interpreting interactions. Newbury, CA: Sage.

Belsky, J., \& Pensky. E. (1990). Developmental history, personality and family relationship: Toward an emergent family system. In R. A. Hinde \& J. Steven-Hinde (Eds.), Relationships within families (pp. 193-217). Oxford, England: Oxford.

Bowlby, J. (1969). Attachment and loss: Vol. I. Attachment. London: The Hogarth Press.

Bowlby, J. (1973). Attachment and loss: Vol. II. Separation, anxiety and anger. London: The Hogarth Press.

Calkins, S. D. (1994). Origins and outcomes of individual differences in emotional regulation. Monographs of the Society for Research in Child Development, 59(2-3), 53-72. doi:10.1111/j.1540-5834.1994.tb01277.x

Cole, P. M., Martin, S. E., \& Dennis, T. A. (2004). Emotion regulation as a scientific construct: Methodological challenges and directions for child development research. Child Development, 75(2), 317-333.

Cowan, P. A., Cohn, D. A., Cowan, C. P., \& Pearson, J. L. (1996).
Parents' attachment histories and children's externalizing and internalizing behaviors: Exploring family systems models of linkage. Journal of Consulting and Clinical Psychology, 64(1), 53-63.

Denham, S. A., Renwick-Debardi, S., \& Hewes, S. (1994), Emotional communication between mothers and preschoolers: Relations with emotional competence. Merrill-Palmer Quarterly, 40(4), 488-508.

Eisenberg, N., \& Fabes, R. A. (1994). Mothers' reactions to children's negative emotions: Relations to children's temperament and anger behavior. Merrill-Palmer Quarterly, 40(1), 138-156.

Eisenberg, N., Cumberland, A., \& Spinard, T. L. (1998). Parental socialization of emotion. Psychological Inquiry, 9(4), 241273.

Goleman, D. (1995). Emotional intelligence: Why it can matter than IQ. New York: Bantam Books.

Hayes, A. F. (2013). Introduction to mediation, moderation, and conditional process analysis: A regression-based approach. New York: Guilford Press.

Lambert, M. (1992). Medieval heresy. Oxford: Blackwell.

MacKinnon, D. P., Lockwood, C. M., Hoffman, J. M., Stephen G., West, S. G., \& Sheets. V. (2002). A comparison of methods to test mediation and other intervening variable effects. Psychological Methods, 7(1), 83-104.

Muller, D., Judd, C. M., \& Yzerbyt, V. Y. (2005). When moderation is mediated and mediation is moderated. Journal of Personality and Social Psychology, 89(6), 852-863.

Morris, A. S., Silk, J. S., Steinberg, L., Myers, S. S., \& Robinson, L. R. (2007). The role of the family context in the development of emotion regulation. Social Development, 16, 361-388.

Preacher, K. J., Rucker, D. D., \& Hayes, A. F. (2007). Addressing moderated mediation hypothesis: Theory, method and prescriptions, Multivariate Behavioral Research, 42(1), 185227.

Preacher, K. J., \& Selig, J. P. (2012). Advantages of Monte Carlo confidence intervals for indirect effects. Communication Methods and Measures, 6(2), 77-98.

Salovey. P., \& Mayer, J. P. (1996). What is emotional intelligence? In. D. Salovey \& D. J. Sluyter (Eds.), Emotional developmental intelligence: Educational implications (pp. 3-34). New York: Basic Books.

Scott, D. M., Barry L. D., Mark A. H., Mark H., \& Barry D. (1996). Escape from Babel: Toward a unifying language for psychotherapy practice. New York: W. W. Norton.

Shortt, J. W., Stoolmiller, M., Smith-Shine, J. N., Eddy, J. M., \& Sheeber, L. (2010). Maternal emotion coaching, adolescent anger regulation, and siblings' externalizing symptoms. Journal of Child Psychology and Psychiatry, 51(7), 799-808.

Shrout, P. E., \& Bolger, N. (2002). Mediation in experimental and non-experimental studies: New procedures and 
recommendations. Psychological Method, 7(4), 422-445.

Trumpeter, N. N., Watson, P. J., O’leary, B. J., \& Weathington, B. L. (2008). Self-functioning and perceived parenting: Relations of parental empathy and love inconsistency with narcissism, depress, and self-esteem. The Journal of Genetic Psychology, 169(1), 51-71.

Valiente, C., Lemery-Chalfant, K., \& Reiser, M. (2007). Pathways to problem behaviors: Chaotic homes, parent and child effortful control, and parenting. Social Development, 16(2), 249-267.

Wu, A. D., \& Zumbo, B. D. (2007). Understanding and using mediators and moderators. Social Indicators Research, 87(3), 367-392.

Yap, M. B. H., Allen, N. B., Leve, C., \& Katz, L. F. (2008). Maternal meta-emotion philosophy and socialization of adolescent affect: The moderating role of adolescent temperament. Journal of Family Psychology, 22(5), 688-703.

\section{In Korean}

Chang, Y.-S., \& Cho, Y.-S. (2014). Parenting attitude: The effects of a mother's childhood experience and parental role satisfaction. The Journal of Korea Open Association for Early Childhood Education, 19(4), 145-163.

Chae, J.-Y., \& Lee, K. (2009). The influences of mothers' childhood attachment representations on preschoolers' social competence: Examining mothers' parenting behaviors as mediators. The Korean Journal of Human Development, 16(4), 95-114

Choi, W.-K., \& Kim, J.-S. (2012). The relation between stress and suicide ideation among college students: The moderating and mediating effects of cognitive emotion regulation. Korea Journal of Counseling, 13(1), 255-272.

Jeun, H.-J. (1996). The effect of childhood experience, personality and marital satisfaction on child-rearing behavior (Master's thesis). Retrieved from http://www.riss.kr/link?id=T937914

Jeong, M. K., \& Kim, Y. H. (2003). Maternal parenting experience, depression, marital conflict, and parenting behavior predicting school children's maladjustment. Family and Environment Research, 14(8), 123-137.

Jeong, O. B., Jeong, S. H., \& Lim, J. H. (2007). Emotional development \& emotional intelligence. Seoul: Hakjisa.

Jeong, Y., \& Park, H. (2012). Korean parent's belief about children's emotion and emotion related parenting. The Korean Journal of Developmental Psychology, 25(2), 107-128.

Jeong, Y. J. (2008). Attachment experience in childhood, personality characteristics, parenting stress, and parenting behavior among mothers with preschool children. Family and Environment Research, 46(3), 73-85.

Hong, S. H. (2000). The criteria for selecting appropriate fit indices in structural equation modeling and their rationales. Korean Journal of Clinical Psychology, 19(1), 161-177.

Kim, G. S. (2010). (AMOS 18.0) Structural equation modeling analysis. Seoul: Hannarae Academy.

Kim, E.-K., \& Ha, Y.-R. (2010). The differences of mothers' attitude toward children's emotional expressiveness, mothers' childhood experience, preschoolers' emotional ability and peer competence by peer status group. Early Childhood Education Research \& Review, 14(2), 171-192.

Kim, E.-K., \& Song, Y.-H. (2009). A study on the relation between mother's childhood experience, mother's emotional regulation style, mother's attitude toward her child's emotional expressiveness and preschoolers' emotional ability. The Journal of Play Therapy, 15(2), 127-144.

Kwon, Y.-I. (2011). A study on how a mother's parenting behaviors is affected by her childhood experience. The Korean Journal of Child Education. 20(2), 85-96.

Lee, J., \& Kim, S.-Y. (2016). Item parceling: Understanding and applying the principles. The Korean Journal of Psychololgy: Genaral, 35(2), 327-353.

Lee, J. S., \& Chung, M. J. (2007). Children's perception of their mother's child-rearing behaviors in relation to the mothers' childhood experiences, satisfaction as a parent and spousal support in parenting. Family and Environment Research, 45(5), 85-94.

Lee, J.-Y., \& Choi, W.-Y. (2012). The mediating effects of cognitive emotion regulation strategies in the relation between college students social supports and psychological wellbeing. Korea Journal of Counseling, 13(3), 1481-1499.

Lee, M.-S., Lee, K.-S., Park, J.-A., \& Shin, Y.-J. (2008). The relationship between attachment classification of children with anxiety disorder and their mothers' childhood experiences. The Korean Journal of Rehabilitation Psychology, 15(1), 33-51.

Lee, S.-H., Lee, O.-K., \& Min, M.-H. (2006). The effects of children's gender, parental divorce, and children's perception of parenting behaviors on children's behavior problems. The Journal of Korean Home Management Association, 24(1), 181-192.

Lim, H. S. (2001). Child's sex, temperament, mother's emotion regulation, and parenting as related to child's emotion regulation (Doctoral dissertation). Retrieved from http:// www.riss.kr/link?id=T10396836

Moon, H. (2001). A study of parental satisfaction and childrearing practices. Family and Environment Research, 39(1), 205-219.

Oh, J.-H. (2013). The development and validity of a scale for measuring mother's reaction to children's negative emotions (Doctoral dissertation). Retrieved from http://www.riss.kr/ link?id=T13054289

Oh, J.-H. (2014). The mediating effects of children's resilience by 
gender on the relationships between mother's reactions to children's negative emotions and children's emotional intelligence. Korean Journal of Child Studies, 35(4), 61-78.

Oh, J.-H. (2015). The effect of mother's reactions to children's negative emotions on children's peer relations: The mediating role of children's empathy and emotional regulation types. Korean Journal of Child Studies, 36(2), 17-37.

Shin, Y.-J. (2014). Mediation effects of emotion regulation abilities on the relationship between social support and perceived stress. Korean Journal of Youth Studies, 21(8), 243-263.

Yoon, H. J. (1993). Perception of everyday stress and social network support in adolescence (Master's thesis). Retrieved from http://www.riss.kr/link?id=T40085

Yu, J. P. (2012). Structural equation modeling concept and understanding. Seoul: Hannarae Academy.

Yu, J. P. (2014). Structural equation modeling misunderstanding and prejudice. Seoul: Hannarae Academy.

Yu, J. P. (2015a). The study of mediated moderating model and moderated mediating model on structural equation modeling and regression: Focusing on satisfaction, trust, dependence and commitment. Journal of Product Research, 33(4), 45-56.

Yu, J. P. (2015b). The item parceling bias of multi-dimensionality in the structural equation modeling. Korean Management Review, 44(4), 1131-1147.

\section{ORCID}

Ji-Hyun Oh http://orcid.org/0000-0001-9846-4310

Received June 30, 2016

Revision received August 18, 2016

Accepted August 22, 2016 